Loma Linda University

TheScholarsRepository@LLU: Digital Archive of Research, Scholarship \& Creative Works

Loma Linda University Electronic Theses, Dissertations \& Projects

6-1997

\title{
A Study of Craniofacial Growth in Infant Heart Transplant Recipients Receiving Cyclosporine
}

David G. Niles

Follow this and additional works at: https://scholarsrepository.llu.edu/etd

Part of the Oral and Maxillofacial Surgery Commons, and the Orthodontics and Orthodontology Commons

\section{Recommended Citation}

Niles, David G., "A Study of Craniofacial Growth in Infant Heart Transplant Recipients Receiving Cyclosporine" (1997). Loma Linda University Electronic Theses, Dissertations \& Projects. 929.

https://scholarsrepository.llu.edu/etd/929

This Thesis is brought to you for free and open access by TheScholarsRepository@LLU: Digital Archive of Research, Scholarship \& Creative Works. It has been accepted for inclusion in Loma Linda University Electronic Theses, Dissertations \& Projects by an authorized administrator of TheScholarsRepository@LLU: Digital Archive of Research, Scholarship \& Creative Works. For more information, please contact scholarsrepository@llu.edu. 


\title{
LOMA LINDA UNIVERSITY \\ Graduate School
}

\section{A STUDY OF CRANIOFACIAL GROWTH IN INFANT HEART TRANSPLANT RECIPIENTS RECEIVING CYCLOSPORINE}

\author{
by \\ David G. Niles
}

\begin{abstract}
A Thesis in partial fulfillment
of the requirements for the Degree Master of

Science in Orthodontics
\end{abstract}


Each person whose signature appears below certifies that this thesis in their opinion is adequate, in scope and quality, as a thesis for the degree Master of Science.

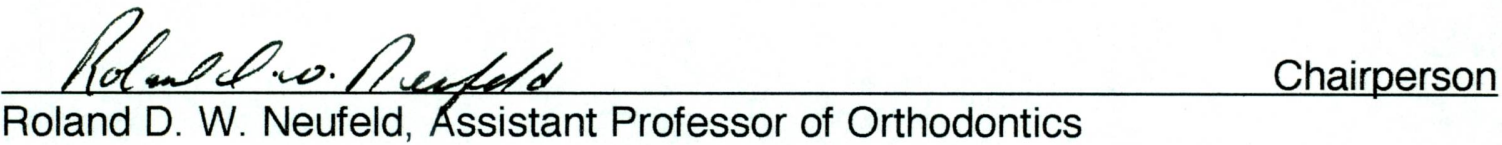

Roland D. W. Neufeld, Assistant Professor of Orthodontics

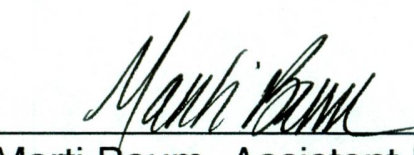

Marti Baum, Assistant Professor of Pediatrics

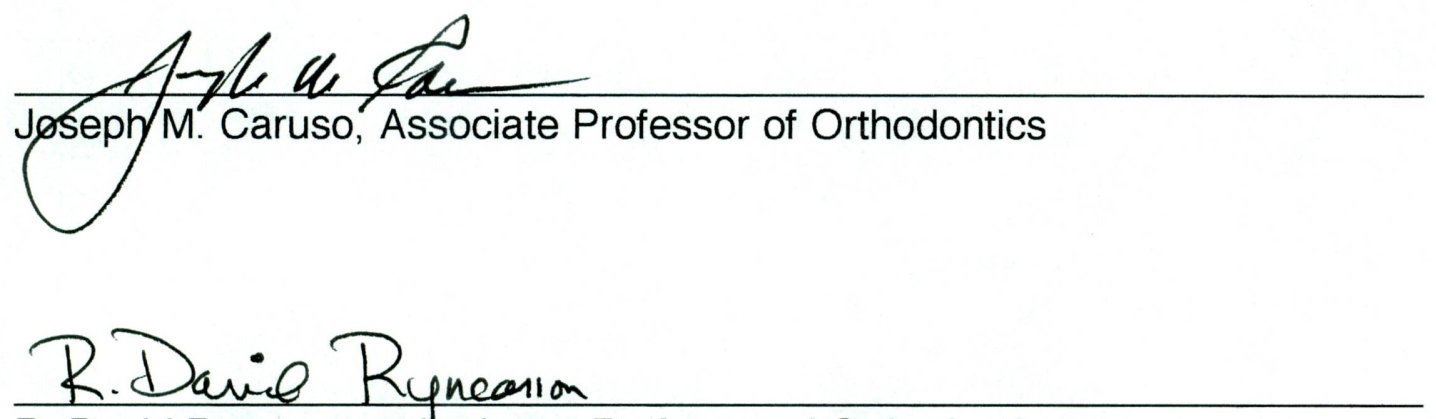

R. David Rynearson, Assistant Professor of Orthodontics 


\section{ACKNOWLEDGMENTS}

I would like to express my appreciation to the individuals who helped me complete this study. I am grateful to Grenith Zimmerman for providing statistical support. I wish to thank R. David Rynearson, Marti Baum, and V. Leroy Leggitt for their advice and guidance in preparation of this manuscript. I wish to thank the other members of my guidance committee, Roland D. W. Neufeld and Joseph M. Caruso for their advice and comments. I am also grateful to Janette Allen for her help in organizing patient records and data collection. I also wish to thank Michael McLeary for his analysis of the carpal index radiographs.

This work was supported by a Seed Grant from the Office of Sponsored Research at Loma Linda University and in part by the Foundation for Orthodontic Research. 
TABLE OF CONTENTS

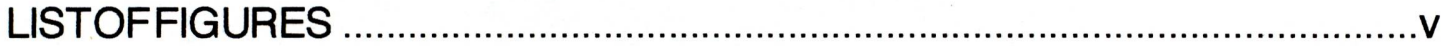

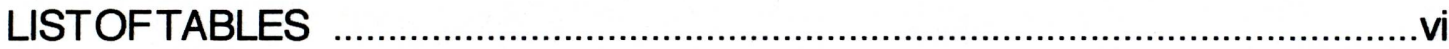

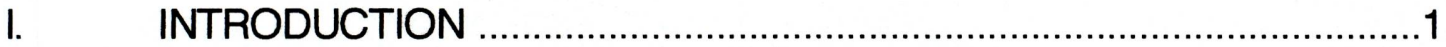

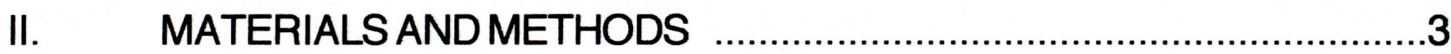

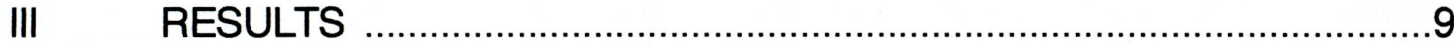

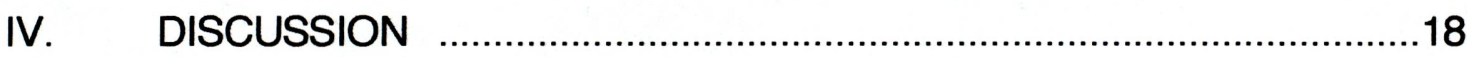

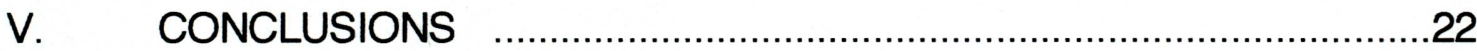

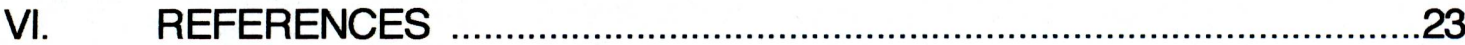




\section{LIST OF FIGURES}

Figure

Page

1. Cephalometric landmarks used .5

2. Cephalometric planes and angles used 6

3. Cephalometric planes and angles used .7 


\section{LIST OF TABLES}

Table

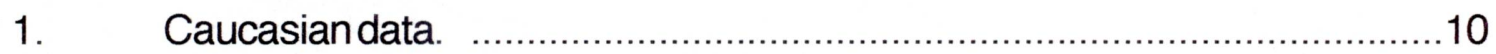

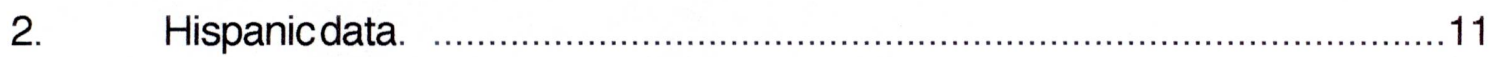

3. Caucasian lateral cephalometric measurements and descriptive

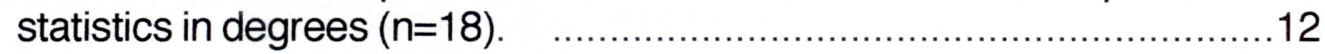

4. Hispanic lateral cephalometric measurements and descriptive statistics in degrees $(n=10)$.

5. Distribution of individuals about the normative mean

(Caucasian $(C) n=18$, Hispanic $(H) n=10$ ).

6. Hand/wrist radiographic data and analysis.

7. Height(Ht.), weight(Wt.), and head circumference(HC.)

growth percentile data. 


\title{
ABSTRACT
}

\section{A STUDY OF CRANIOFACIAL GROWTH IN INFANT HEART TRANSPLANT RECIPIENTS RECEIVING CYCLOSPORINE}

\author{
by \\ David G. Niles
}

Cyclosporine is an effective immunosuppressive drug that has found widespread application in organ transplantation. However, a few studies have implicated cyclosporine as adversely affecting craniofacial growth in the pediatric population. The purpose of this study was to evaluate the possible untoward effects of cyclosporine long-term on craniofacial growth in a group of infant heart transplantation recipients. A prospective group $(n=28)$ of eighteen Caucasian children (9 female and 9 male, ages 4-10 years) and ten Hispanic children ( 3 female and 7 male, ages $4-10$ years) were evaluated. None of the subjects had undergone orthodontic therapy. All subjects had heart transplantation before six months of age and followed the Loma Linda University International Pediatric Heart Transplantation Immunosuppression protocol. The primary immunosuppression agent was cyclosporine with azathioprine or methotrexate. Rescue therapy for graft rejection consisted of glucocorticoid and/or polyclonal antibody therapy. None of the subjects received the immunosupressant tacrolimus (FK506). Using lateral cephalometric radiography, seven skeletal angular measurements (SNA, SNB, ANB, GoGn-SN, NA-Pog, ArGoMe, NPog-AB) were examined and compared to 
contemporary growth standards. Hand/wrist radiographs were evaluated for bone age. Also, longitudinal height, weight, and head circumference data was obtained and compared to standardized growth and development curves. Descriptive statistics was used to summarize the data. Cephalometrically, $86 \%$ $(\mathrm{N}=24)$, showed minor deviation from mean normative values. Four subjects (14\%) did show cephalometric measures indicative of individuals with a vertical growth pattern. Analysis of the hand/wrist radiographs showed all but one subject to have normal bone age. Height, weight, and head circumference data revealed a wide range of growth percentiles for the entire group with mean percentiles in the range of $25 \%-50 \%$. The findings of this pilot study indicate that, in general, skeletal growth of the craniofacial complex as well as axial skeletal growth was not significantly altered by the immunosuppressive regimen of cyclosporine over the time period evaluated. Further longitudinal data compiled from this study may shed more light on the possible adverse effects of cyclosporine on craniofacial growth and development. 


\section{INTRODUCTION}

The last decade and a half has witnessed the extension of heart transplantation therapy into the pediatric population. The scope of cardiac lesions which leads to heart transplantation includes children and infants with cardiomyopathies, cardiac tumors, and complex congenital heart disease. The most common cyanotic congenital heart disease is hypoplastic left heart syndrome. Recent actuarial data of infants and children undergoing cardiac transplantation supports a positive prognosis which parallels that of adults. 1,2,3 Much of this success can be attributed to posttransplantation immunomodulation, surgical experience, improved technology for graft surveillency, and better patient selection. 1 What was once a procedure with high perioperative mortality, is now routine medical intervention for end stage cardiac disease in the pediatric population. 4

Decreased organ transplantation graft rejection may be attributed to better management of posttransplantation immunomodulation of which several therapeutic regimens have been advocated.1,2,3,4,6 The most common immunosuppression therapies are based on cyclosporine or FK506 in combination with adjunctive agents, such as azathioprine and glucocorticoid. 1,2

The unique action of cyclosporine on T-cell immunosuppression without myelosuppression has established it as a first line therapy for graft maintenance.6 However, the adverse effects of cyclosporine, including nephrotoxicity, lymphoproliferative disease, hypertension, gingival hyperplasia, and hypertrichosis are well documented in the literature.5,6,7,8,9,10 In 
addition to these side effects, studies by Reznik et al linked cyclosporine to abnormal facial growth in pediatric renal transplant patients. Initial investigations by Reznik et al . (1987), revealed thickening of the nares, lips and ears, puffiness of the cheeks, prominence of the supraorbital margins, and mandibular prognathism. The changes in facial appearance resembled those seen with phenytoin therapy. ${ }^{11}$ A follow-up study by Reznik et al. (1989), evaluated the effects of cyclosporine on facial bone growth. The results showed a relative shortening of the posterior face height, an increase in anterior face height, a steep mandibular plane angle, an absolute shortening of the mandibular body and mandibular retrognathia. These characteristics are often seen in patients with long face syndrome.14 These findings have raised some important questions concerning possible dysmorphic craniofacial growth and has been the impetus for this study.

The purpose of this paper is twofold. Firstly, it is to initiate the formation of a longitudinal study to evaluate the effects of long-term cyclosporine immunosuppression on craniofacial growth in the pediatric heart transplanted patient treated in the International Pediatric Heart Transplantation Program at Loma Linda University's Childrens Hospital. Secondly, it is a pilot study with the intent to gather initial patient data and compare this with normative growth study data. 


\section{MATERIALS AND METHODS}

A prospective group of twenty-eight pediatric heart transplantation patients currently on maintenance cyclosporine based immunosuppression therapy were evaluated. Inclusion criteria for this study was limited to pediatric patients who required a heart transplantation at Loma Linda University before six months of age and who were 4 years of age or older at the beginning of the study. Children with associated genetic problems, hormonal deficiencies, major organ failures, and other related syndromes were excluded from this evaluation in an effort to minimize confounding variables. The composition of the study group was as follows: eighteen subjects were Caucasian of European ancestry (9 female and 9 male, ages 4-10 years) and ten were of Hispanic decent ( 3 females and 7 males, ages 4-7 years). Age groups were determined by including in each age interval, radiographs taken six months before a birth month through five months after a birth month. 15

All patients followed the Loma Linda University International Pediatric Heart Transplantation immunosuppression protocol. The primary posttransplantation immunosuppression agent was cyclosporine with decreasing doses of azathioprine or methotrexate. Target radioimmunoassay (RIA) whole blood levels of cyclosporine were maintained at therapeutic doses of $150-350 \mathrm{ng} / \mathrm{dl}$. The use of adjunctive agents such as polyclonal antibody therapy and/or pulse glucocorticoids was limited to severe or chronic graft rejection. None of the patients received the immunosuppressive agent tacrolimus (FK506).

Data was gathered on each patient in an effort to conduct a craniofacial growth analysis. Each child had a lateral cephalograph, panoramic 
radiograph, hand/wrist radiograph, and a standard orthodontic photographic series (frontal, frontal smiling, profile, and intra-oral). In addition, height and weight data was obtained from age three until the time of study initiation. Head circumference data was also recorded until the age of three.

Cephalographs were obtained by the Broadbent cephalometric technique which positions the subject's head in a cephalostat oriented to the Frankfort horizontal plane. An anode-to-object distance of five feet was used. 16 The object-to-film distance was standardized at $13 \mathrm{~cm}$ which produces a consistent $9 \%$ enlargement factor. Standard anatomical landmarks from each cephalograph were identified and traced on standard 0.003 inch acetate matte tracing paper by the principal investigator. Each landmark location was reviewed by at least one other investigator before computer digitization. The cephalometric analysis was completed using the Quick ceph image pro software program.

The following landmarks were identified on each lateral $\mathrm{x}$-ray film (Fig 1): sella turcica $(S)$, nasion $(N)$, point $A(A)$, point $B(B)$, pogonion (Pog), gnathion (Gn), gonion (Go), menton (Me), and articulare (Ar).

The definitions for these landmarks have been widely published. 15,20 Various angular measurements have been derived from these landmarks which have been described in the classic literature.17,18,19 The skeletal angular parameters examined in this study were as follows: Fig. 2. SNA, SNB, ANB, GoGn-SN, Angle of Convexity (NAPog) and Fig. 3. Gonial angle (ArGoMe), A-B Plane (NPog-AB). Descriptive statistics were used to compare the acquired cephalometric data with normative non-medically compromised subject data. 


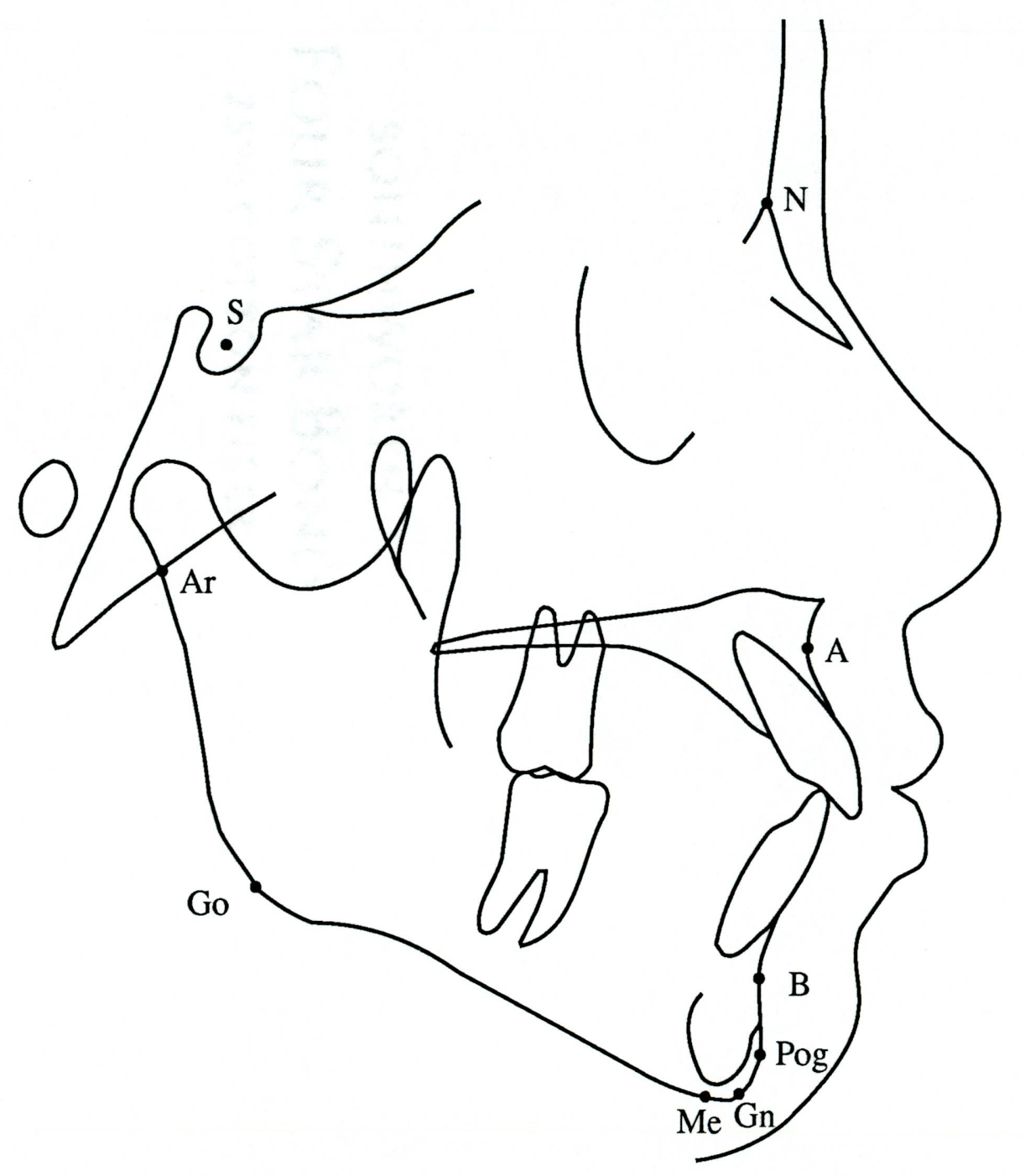

Fig. 1. Cephalometric landmarks used 


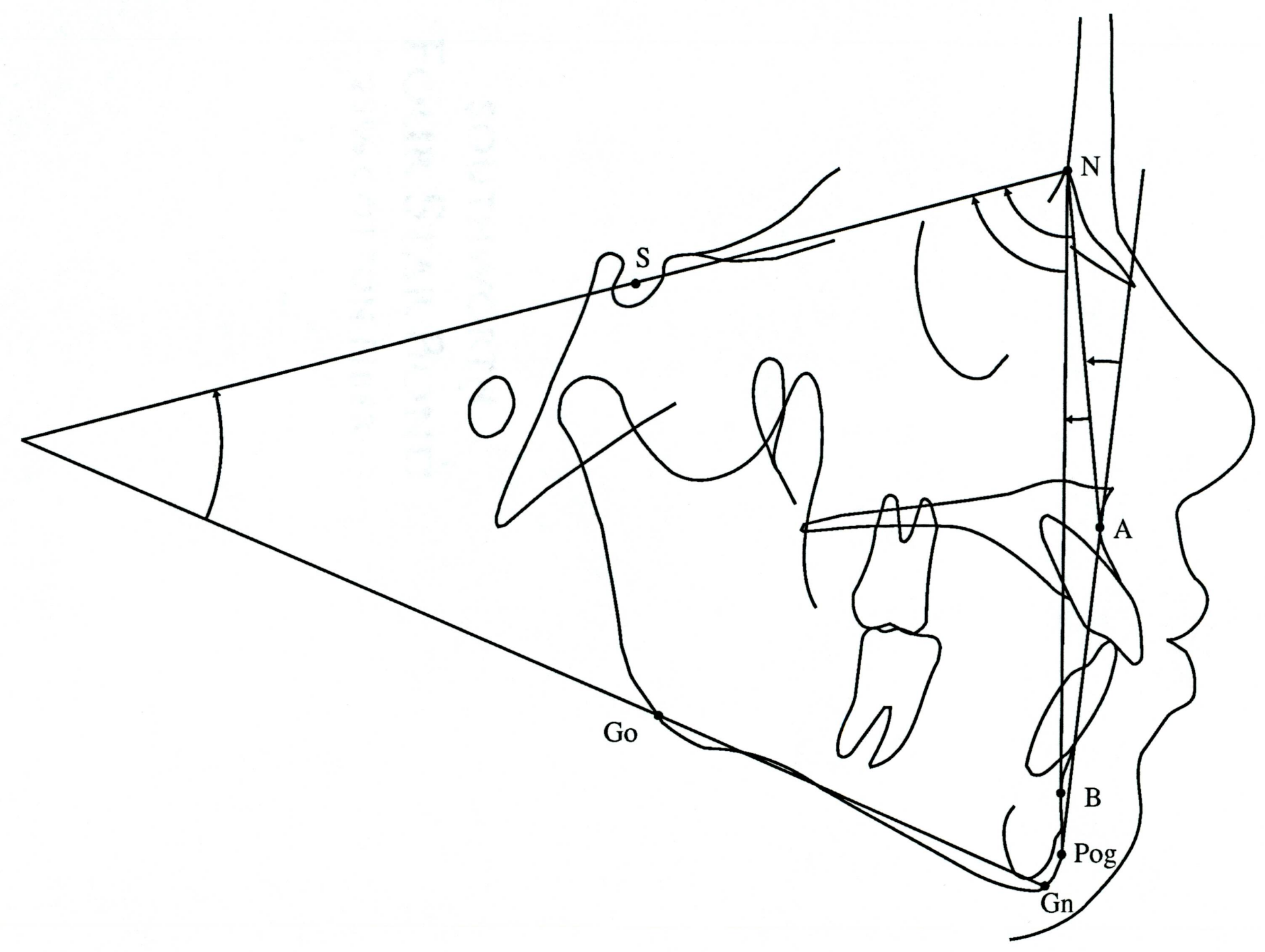

Fig. 2. Cephalometric planes and angles 


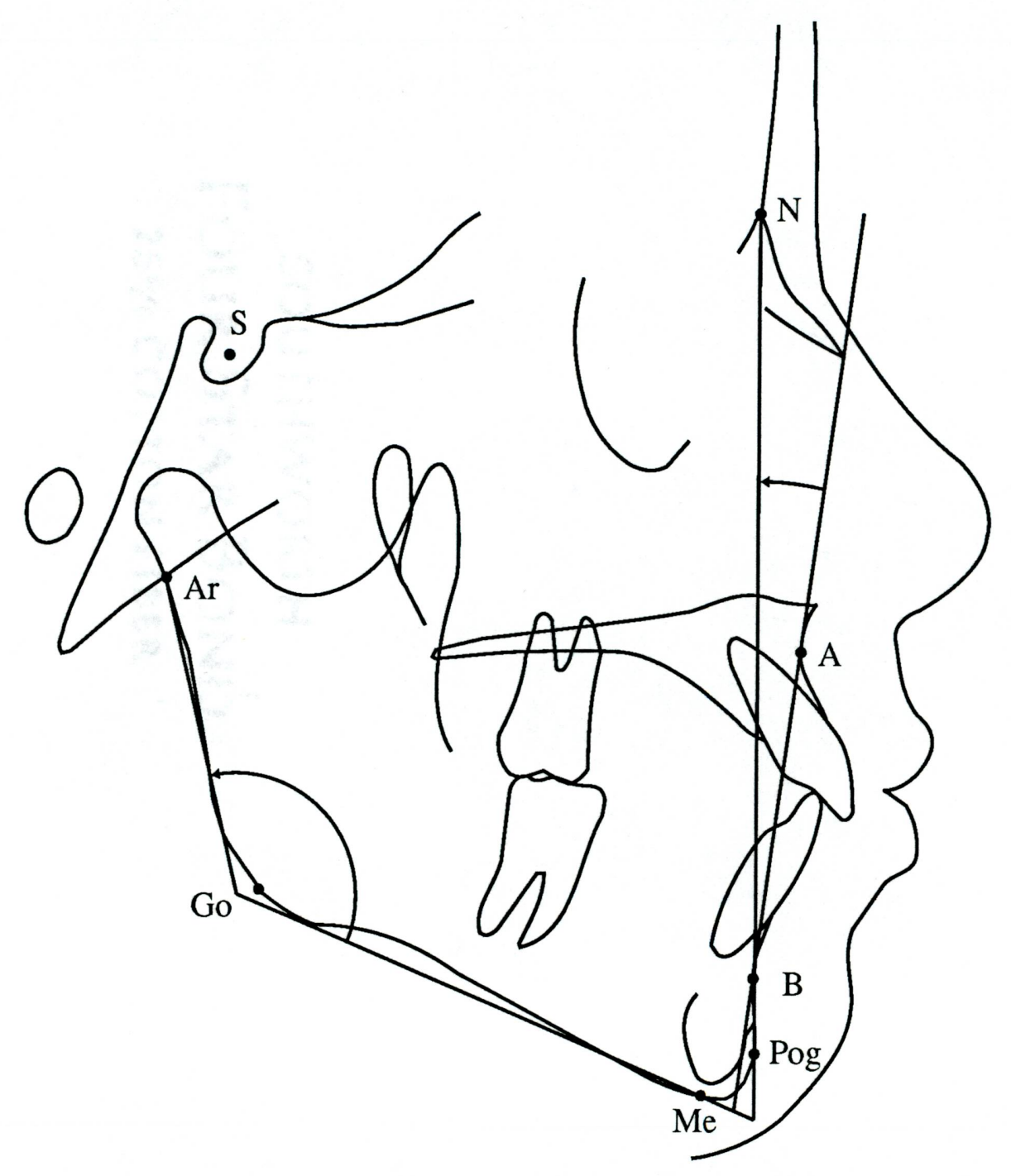

Fig. 3. Cephalometric planes and angles 
Caucasian subjects were analyzed against the normative standards from the Michigan growth study. 15 This comparative database was compiled in Ann Arbor and involved a typical non-medically compromised group of normal growing children including those with mild and moderate malocclusions. The Hispanic subjects were analyzed against crossectional data obtained through research at the University of Texas at Houston. 12, 21 All children of this group had normal profiles and Angle Class I occlusions. This sample, although not typical of a random population represents an adequate database for comparison and is one of the largest databases available.

A standard right hand carpal index was taken with hand and wrist of each subject in full contact with the film cassette with no focusing grid in place. This produces a less than measurable amount of magnification. Each hand/wrist radiograph was compared to Greulich and Pyle's Radiographic Atlas of Skeletal Development of the Hand and Wrist and analyzed for axial skeletal growth deviations by a pediatric radiologist from the Loma Linda University Medical Center.22

Height and weight data was gathered from the age of three for 27 of the 28 subjects. The last measurements were used for percentile ranking. Head circumference measurements were recorded at about 36 months of age. Data for the entire group was plotted and analyzed against standard prepubescent growth and development statistics percentiles data from the National Center for Health Statistics. 23 


\section{RESULTS}

The cephalometric skeletal angular parameter values for individuals of the Caucasian and Hispanic groups are recorded in Tables 1 and 2, respectively.

Tables 3 and 4 shows the descriptive statistical data and mean normative values for each cephalometric parameter recorded. Table 3 indicates that the difference between the Caucasian mean norms and the recorded mean values range from 0.0 to 0.5 degrees for six of the seven parameter measurements, with the Gonial angle value differing by 3.9 degrees. Table 4 lists the above mentioned statistical measurementst for the Hispanic group. The difference between the mean norms and recorded mean values in this group range from 0.8 to 3.7 degrees. The mean and median values for both groups were quite close with a difference ranging from 0.1 to 0.9 and 0.1 to 1.7 degrees, respectively.

Table 5 indicates the distribution of individuals in each of the two groups studied within 1, 2 and greater than 2 standard deviations for each angular parameter value measured. The majority of the subjects were within 2 standard deviations of the norm for each measurement. These findings would suggest a relatively normal pattern of facial growth for the majority of this sample. The most common cephalometric measurements greater than 2 standard deviations from the norm were GoGn-SN, Gonial angle, and ANB angle. However, only four subjects (\#5,\#7,\#8, \&\#13) exhibited a pattern of growth similar to those implicated in Reznik's investigation, that of steep mandibular plane angle and mandibular retrognathia. 14 
Table 1. Caucasian lateral cephalometric data.

$\begin{array}{cccccccc}\text { Subject } & \text { SNA } & \text { SNB } & \text { ANB } & \begin{array}{c}\text { GoGn- } \\ \text { S N }\end{array} & \begin{array}{c}\text { Angle of } \\ \text { Convexity }\end{array} & \begin{array}{c}\text { Gonial } \\ \text { Angle }\end{array} & \begin{array}{c}\text { A-B } \\ \text { Plane } \\ \text { Angle }\end{array} \\ & & & & & & & \\ 1 & 76.7 & 72.6 & 4.0 & 48.4 & 8.9 & 142.6 & -5.4 \\ 2 & 85.8 & 80.1 & 5.7 & 37.4 & 12.4 & 128.4 & -6.5 \\ 3 & 82.0 & 75.5 & 6.5 & 38.9 & 12.8 & 135.3 & -8.0 \\ 4 & 78.3 & 74.8 & 3.5 & 28.5 & 6.4 & 127.8 & -5.7 \\ 5 & 80.3 & 72.6 & 7.8 & 43.9 & 18.8 & 138.4 & -9.0 \\ 6 & 86.4 & 80.4 & 6.0 & 43.2 & 14.4 & 143.5 & -6.9 \\ 7 & 80.8 & 71.1 & 9.7 & 46.9 & 20.6 & 139.1 & -8.7 \\ 8 & 84.9 & 77.1 & 7.8 & 44.3 & 18.5 & 139.5 & -5.4 \\ 9 & 84.0 & 81.8 & 2.2 & 34.2 & 4.0 & 135.2 & -3.1 \\ 10 & 84.3 & 81.0 & 3.4 & 36.9 & 7.9 & 137.4 & -4.2 \\ 11 & 80.9 & 75.1 & 5.9 & 33.9 & 10.7 & 130.3 & -7.0 \\ 12 & 80.0 & 74.8 & 5.2 & 33.0 & 4.3 & 119.7 & -9.3 \\ 13 & 83.0 & 73.2 & 9.8 & 44.4 & 22.0 & 138.4 & -10.6 \\ 14 & 78.6 & 77.2 & 1.4 & 41.2 & 2.5 & 130.6 & -2.1 \\ 15 & 79.0 & 71.6 & 7.4 & 43.4 & 14.7 & 130.8 & -9.6 \\ 16 & 82.1 & 79.4 & 2.7 & 35.0 & 4.0 & 128.6 & -4.4 \\ 17 & 79.2 & 73.6 & 5.5 & 40.2 & 11.6 & 127.2 & -8.1 \\ 18 & 82.9 & 79.6 & 3.3 & 37.9 & 8.0 & 141.9 & -2.4\end{array}$


Table 2. Hispanic lateral cephalometric data.

$\begin{array}{cccccccc}\text { Subject } & \text { SNA } & \text { SNB } & \text { ANB } & \begin{array}{c}\text { GoGn- } \\ \text { S N }\end{array} & \begin{array}{c}\text { Angle of } \\ \text { Convexity }\end{array} & \begin{array}{c}\text { Gonial } \\ \text { Angle }\end{array} & \begin{array}{c}\text { A-B } \\ \text { Plane } \\ \text { Angle }\end{array} \\ & & & & & & & \\ 19 & 82.2 & 77.0 & 5.2 & 39.6 & 12.8 & 125.2 & -3.9 \\ 20 & 85.1 & 76.4 & 8.6 & 42.0 & 20.5 & 127.8 & -8.4 \\ 21 & 82.0 & 79.6 & 2.4 & 40.8 & 6.4 & 145.8 & -1.6 \\ 22 & 89.0 & 80.4 & 8.6 & 33.4 & 15.5 & 136.5 & -8.6 \\ 23 & 79.2 & 76.2 & 3.1 & 36.4 & 8.0 & 129.5 & -3.1 \\ 24 & 80.8 & 77.3 & 3.5 & 36.5 & 8.2 & 133.1 & -3.5 \\ 25 & 84.2 & 80.4 & 3.8 & 37.4 & 8.4 & 130.3 & -4.5 \\ 26 & 84.7 & 80.5 & 4.2 & 36.4 & 10.7 & 127.2 & -5.5 \\ 27 & 85.7 & 79.9 & 5.8 & 37.8 & 13.5 & 129.8 & -6.0 \\ 28 & 80.5 & 76.7 & 3.8 & 36.4 & 9.7 & 132.5 & -4.4\end{array}$


Table 3. Caucasion lateral cephalometric measurements and descriptive statistics in degrees $(n=18)$

\section{NORMS}

\begin{tabular}{|c|c|c|c|c|c|c|c|c|}
\hline MEASUREMENTS & Mean & SD & Mean & SD & Median & Min. & Max. & Range \\
\hline SNA & 81.3 & 3.0 & 81.6 & 2.8 & 81.5 & 76.7 & 86.4 & 9.7 \\
\hline SNB & 76.0 & 3.0 & 76.2 & 3.5 & 75.3 & 71.1 & 81.8 & 10.7 \\
\hline ANB & 5.4 & 2.5 & 5.4 & 2.5 & 5.6 & 1.4 & 9.8 & 8.4 \\
\hline GoGn-SN & 40.0 & 4.7 & 39.5 & 5.4 & 39.6 & 28.5 & 48.4 & 19.9 \\
\hline Angle of Convexity & 11.3 & 5.2 & 11.3 & 6.0 & 11.2 & 2.5 & 22.0 & 19.5 \\
\hline Gonial Angle & 130.3 & 4.5 & 134.2 & 6.5 & 135.3 & 119.7 & 143.5 & 23.8 \\
\hline A-B Plane Angle & -6.7 & 3.4 & -6.5 & 2.6 & -6.7 & -2.1 & -10.6 & 8.5 \\
\hline
\end{tabular}

\section{PATIENT DATA}


Table 4. Hispanic lateral cephalometric measurements and descriptive statistics in degrees $(n=10)$

NORMS

$\begin{array}{lcccccccc}\text { MEA SUREMENTS } & \text { Mean } & \text { SD } & \text { Mean } & \text { SD } & \text { Median } & \text { Min. } & \text { Max. } & \text { Range } \\ \text { SNA } & 82.3 & 3.1 & 83.3 & 2.9 & 83.2 & 79.2 & 89.0 & 9.8 \\ \text { SNB } & 76.4 & 3.0 & 78.4 & 1.9 & 78.5 & 76.2 & 80.5 & 4.3 \\ \text { ANB } & 5.8 & 1.7 & 4.9 & 2.2 & 4.0 & 2.4 & 8.6 & 6.2 \\ \text { GoGn-SN } & 36.5 & 5.7 & 37.7 & 2.5 & 37.0 & 33.4 & 42.0 & 8.6 \\ \text { Angle of Convexity } & 12.2 & 6.6 & 11.4 & 4.3 & 10.2 & 6.4 & 20.5 & 14.1 \\ & & & & & & & & \\ \text { Gonial Angle } & 128.9 & 6.3 & 131.8 & 5.9 & 130.1 & 125.2 & 145.8 & 20.6 \\ \text { A-B Plane Angle } & -1.3 & 6.4 & -5.0 & 2.2 & -4.5 & -1.6 & -8.6 & 7.0\end{array}$


Table 5. Distribution of individuals about the normative mean (Caucasian (C) $n=18$, Hispanic $(H) n=10$ )

$$
<\text { 1SD } \quad \text { 2SD 2SD }
$$

$\begin{array}{lcccccr}\text { MEASUREMENTS } & \text { C } & \text { H } & \text { C } & \text { H } & \text { C } & \text { H } \\ \text { SNA } & 12 & 8 & 6 & 1 & 0 & 1 \\ \text { SNB } & 8 & 6 & 10 & 4 & 0 & 0 \\ \text { ANB } & 11 & 4 & 5 & 5 & 2 & 1 \\ \text { GoGn-SN } & 8 & 10 & 7 & 0 & 3 & 0 \\ \text { Angle of Convexity } & 13 & 8 & 4 & 1 & 1 & 1 \\ \text { Gonial Angle } & 8 & 7 & 7 & 2 & 3 & 1 \\ \text { A-B Plane Angle } & 13 & 8 & 5 & 2 & 0 & 0\end{array}$


Each subjects chronological age was compared with their skeletal age as determined via their hand/wrist radiograph using Gruelich and Pyle's Radiographic Atlas. Table 6 shows that all but one of the individuals analyzed had a normal axial skeletal bone age. Only subject \#11 showed a decreased bone age of greater than 2 standard deviations.

Height, weight, and head circumference data was recorded in Table 7. The mean height and weight percentiles for the entire group was in the $25 \%-50 \%$ range at the onset of the study. The mean head circumference percentiles at the age of three for the entire group was also in the $25 \%-50 \%$ range.

Subjective photographic and panoramic radiographic analysis was also evaluated. The photographic records revealed that many of the patients exhibited mild to moderate hypertrichosis and gingival hyperplasia. Also, it was observed photographically that two individuals (\#12,\#22) did exhibit facial appearance abnormalities similar to those documented by Reznik. 13

Upon radiographic analysis there seemed to be an uncommon propensity for missing permanent teeth and to a lesser degree ankylosed primary molars. Eight or $29 \%$ of the subjects were suspected of missing either maxillary second bicuspids, mandibular second bicuspids, or maxillary laterals or a combination. Five or $18 \%$ of the individuals showed suspected ankylosis of primary molars. 
Table 6. Hand/wrist radiographic data and analysis.

$\begin{array}{cccccc}\text { Subject } & \text { Sex } & \begin{array}{c}\text { Age } \\ \text { yr.-mo. }\end{array} & \begin{array}{c}\text { Bone age } \\ \text { yr.-mo. }\end{array} & \begin{array}{c}\text { S D } \\ \text { mo. }\end{array} & \begin{array}{c}\text { Analysis } \\ \text { (n)normal } \\ \text { (d)delayed }\end{array} \\ & & & & & \\ 1 & \mathrm{~m} & 6-6 & 7-0 & 9.7 & \mathrm{n} \\ 2 & \mathrm{~m} & 5-11 & 5-0 & 9.3 & \mathrm{n} \\ 3 & \mathrm{~m} & 4-6 & 4-6 & 7.8 & \mathrm{n} \\ 4 & \mathrm{~m} & 5-7 & 6-0 & 9.1 & \mathrm{n} \\ 5 & \mathrm{f} & 6-5 & 5-9 & 8.6 & \mathrm{n} \\ 6 & \mathrm{f} & 7-1 & 5-9 & 8.3 & \mathrm{n} \\ 7 & \mathrm{f} & 5-11 & 5-0 & 9.0 & \mathrm{n} \\ 8 & \mathrm{~m} & 7-4 & 7-0 & 10.5 & \mathrm{n} \\ 9 & \mathrm{~m} & 8-4 & 8-0 & 10.8 & \mathrm{n} \\ 10 & \mathrm{f} & 7-5 & 7-10 & 8.5 & \mathrm{n} \\ 11 & \mathrm{~m} & 7-9 & 5-9 & 10.8 & \mathrm{~d} \\ 12 & \mathrm{f} & 10-7 & 8-10 & 11.0 & \mathrm{n} \\ 13 & \mathrm{~m} & 7-7 & 7-0 & 10.6 & \mathrm{n} \\ 14 & \mathrm{~m} & 8-9 & 8-0 & 11.0 & \mathrm{n} \\ 15 & \mathrm{f} & 6-10 & 6-10 & 8.3 & \mathrm{n} \\ 16 & \mathrm{f} & 8-2 & 8-10 & 8.8 & \mathrm{n} \\ 17 & \mathrm{f} & 10-5 & - & - & - \\ 18 & \mathrm{f} & 6-0 & - & - & - \\ 19 & \mathrm{f} & 5-3 & 5-0 & 8.9 & \mathrm{n} \\ 20 & \mathrm{~m} & 4-10 & 6-0 & 7.8 & \mathrm{n} \\ 21 & \mathrm{~m} & 6-6 & 6-0 & 9.7 & \mathrm{n} \\ 22 & \mathrm{~m} & 5-2 & 5-0 & 8.4 & \mathrm{n} \\ 23 & \mathrm{~m} & 6-0 & 5-0 & 9.3 & \mathrm{n} \\ 24 & \mathrm{f} & 5-9 & 5-9 & 9.0 & \mathrm{n} \\ 25 & \mathrm{~m} & 6-11 & 6-0 & 10.1 & \mathrm{n} \\ 26 & \mathrm{~m} & 5-6 & 4-6 & 9.1 & \mathrm{n} \\ 27 & \mathrm{f} & 6-11 & 5-9 & 8.3 & \mathrm{n} \\ 28 & \mathrm{~m} & 7-4 & 7-0 & 10.5 & \mathrm{n}\end{array}$


Table 7. Height(Ht.), weight(Wt.), and head circumference(HC) expressed as a percentile of normative standards for a specific age. $\mathrm{Ht}$. and wt. percentiles were figured from the last recorded entry. The $\mathrm{HC}$ percentiles were from the age of three.

$\begin{array}{llll}\text { Subject } & \text { Ht. } \% & \text { Wt. } \% & \text { HC. } \%\end{array}$

$\begin{array}{cccc}1 & - & - & - \\ 2 & 10-25 & 25-50 & 50 \\ 3 & 25-50 & 10-25 & 75 \\ 4 & 50 & 25-50 & 10-25 \\ 5 & 25-50 & 50-75 & 5-10 \\ 6 & 50 & 25-50 & 25 \\ 7 & 25 & 25-50 & 50-75 \\ 8 & 25-50 & 25-50 & 5-10 \\ 9 & 10-25 & 25 & <5 \\ 10 & 50-75 & 90 & 50-75 \\ 11 & 90 & 75 & - \\ 12 & 5-10 & 10 & 50-75 \\ 13 & 5 & 10-25 & 10-25 \\ 14 & 95 & 50-75 & 95 \\ 15 & 25 & 50 & 50 \\ 16 & 25-50 & 25-50 & 25 \\ 17 & 25 & <5 & 50 \\ 18 & 25-50 & 75 & 25-50 \\ 19 & 75 & >95 & 50 \\ 20 & 10-25 & 50 & 50 \\ 21 & 25-50 & 75-90 & 25-50 \\ 22 & <5 & <5 & 25-50 \\ 23 & 5-10 & 25-50 & 10-25 \\ 24 & 5-10 & 10-25 & 90 \\ 25 & 5 & 5 & - \\ 26 & <5 & 10 & 10-25 \\ 27 & 5 & 5 & <5 \\ 28 & 25-50 & 50 & 50 \\ & & & \\ \text { Mean\%: } & 25-50 & 25-50 & 25-50\end{array}$




\section{DISCUSSION}

Dysmorphic craniofacial growth, or the lack there of, and its relation to a known therapeutic regimen, namely cyclosporine, is the primary interest of this investigation. The effects of cyclosporine have been well documented in the literature.5,6,7,8,10 More recently, this agent has been implicated in adversely affecting craniofacial growth in renal transplantation recipients. 13,14 In order to better understand the long term effects of cyclosporine on growth, we have examined the craniofacial and axial skeletal development of a group of infant heart transplantation recipients and compared them to normative growth data.

Many factors have been implicated in the disturbance of skeletal and craniofacial growth including, trauma, chronic illness, congenital influences, developmental defects, environmental factors, and teratogens. Moreover, there are recognized at least four major components to the complex phenomenon of craniofacial growth and development. These include the cranial base synchondrosis and the calvarial sutures being influenced by the CNS and other soft tissue growth, the nasal-septal cartilage, the remodeling growth of the maxilla and mandible, and the cartilaginous growth at the temporomandibular condyle.24 Certain etiological factors that affect any or all of these components may cause morphometric changes in craniofacial growth patterns. 25

Our cephalometric data revealed that, $86 \%(\mathrm{~N}=24)$, showed minor deviation from mean normative values. Most measures for each subject were within 1 or 2 standard deviations. Four subjects ( \#5,\#7, \#8, \&\#13) did in fact show cephalometric measures indicative of individuals with a vertical growth pattern and apparent mandibular retrognathia as evidenced by an increased 
GoGn-SN angle, ANB angle, and Gonial angle. No definitive conclusions could be drawn concerning the specific etiology of the vertical growth pattern seen in these subjects other than normal variations within a given sample. None of these patients were associated with decreased bone age or facial abnormalities. The fact that the mean and median Caucasian Gonial angle measurement was only one standard deviation from the normative mean for this group seemed inconclusive in relation to cyclosporine.

Only one subject (\#11) revealed a decreased bone age upon carpal index analysis. The facial and skeletal presentation of this patient appeared within normal limits. This would support the idea of a relatively normal pattern of axial skeletal development for this sample.

Longitudinal height and weight data revealed a substantial range in growth percentiles for the group. Mean height and weight percentiles did suggest a potential decreased stature. In fact, when these subjects are subjectively compared to their non-medically compromised siblings there appears to be a tendency for suppressed statural development. Mean head circumference percentiles at age 3 years were similar to the height and weight data obtained. The potental role of chronic illness, individual genetic variability, and teratogenic influence on general growth and development of this sample is not yet clear.

Clinically, only two individuals (\#12, \#22) exhibited a facial appearance similar to those reported by Reznik. Neither of these subjects showed any significant skeletal abnormalities and no single variable could be implicated in the dysmorphic presentation seen. However, the long-term use of 
prednisone in subject \#12 could not be overlooked as a primary etiologic factor in her "cushingoid-like" facial appearance.

It was interesting that eight subjects $(29 \%)$ were suspected of missing one or more permanent teeth and five subjects (18\%) showed ankylosed primary molars. The most commonly found missing teeth were maxillary or mandibular second bicuspids. In light of the fact that the permanent third molars could not be evaluated at this age and that these teeth are by far the most often congenitally missing, one could suspect that it is possible that a higher percentage of subjects could reveal permanent tooth agenesis. This is a significant finding due to the fact that somewhat less than $4 \%$ of the general population have one or more teeth congenitally missing. 26 There are five principal known causes of congenital absence of teeth: heredity, ectodermal tissue dysplasias, local infections, systemic conditions, and expression of evolutionary changes in the dentition. 26 In addition, although primary molar ankylosis is relatively common among the general population it seemed to be more prevalent in our sample, $8 \%$ vs. $18 \%$, respectively. No definitve conclusions could be made concerning the primary etiologic factor for these findings. Additional longitudinal data may shed some light on these interesting findings.

Our data seems to support the fact that, in general, craniofacial growth and skeletal development is not affected by the immunomodulatory regimen utilized in this pilot study. It seems to be questionable as to whether the few facial bone "abnormalities" noted are truly dysmorphic features with definitive etiologies. Interestingly, If one was to gather a matched random 
sample of children from the general population one may in fact find similar outliers as seen in this preliminary study. 


\section{v. CONCLUSIONS}

In conclusion, the morphometric analysis of twenty eight cardiac transplanted children treated with long term cyclosporine immunosuppression shows a relatively normal pattern of growth for the vast majority of the sample studied. Our data did not support the findings of previous reports. Due to the tremendous variability of genetic factors as well as individual responses to chronic illness and therapeutic treatments, it makes it quite difficult to implicate any one immunomodulatory agent as a potential divergent to normal growth and development, at least up to this point in time. The possible role of cyclosporine in adversely affecting craniofacial growth over a longer period of time needs to be evaluated further. Continued longitudinal data collection and evaluation is planned for this pilot sample and for a larger sample size. 


\section{REFERENCES}

1. Armitage JM, Fricker FJ, del Nido P, Starzl TE, Hardesty RL, Bartley PG. A decade (1982-1992) of pediatric cardiac transplantation and the impact of FK506 immunosuppression. J Thorac Cardiovasc Surg 1993; 105:465-473.

2. Bailey LL. Pediatric heart transplantation. Ann Thorac Surg 1989; 48:612.

3. Trento A, Griffith BP, Fricker FJ, Kormos RL, Armitage JM, Hardesty RL. Lessons learned in pediatric hear $t$ transplantation. Ann Thorac Surg 1989; 48:617-621.

4. Bailey LL, Assaad AN, Trimm RF, Nehlsen-Cannarella SL, Kanakriyeh MS, Haas GS, Jacobson JG. Orthotopic transplantation during early infancy as therapy for incurable congenital heart disease. Ann Surg Sept. 1988; 279-285.

5. Kahan BD, Flechner SM, Lorber MI, Jensen C, Golden D, Van Buren CT. Complications of Cyclosporine Therapy. World J Surg. 1986; 10: 348-360.

6. Bennett WM, Norman DJ, Action and Toxicity of Cyclosporine. Ann Rev Med 1986; 37:215-224.

7. Palestine AG, Nussenblatt RB, Chan C. Side Effects of Systemic Cyclosporine in Patients not Undergoing Transplantation. Am J Med 1984; 77:652-56.

8. Drugs. June, 1993; 45(6): 953-1040.

9. Wallemacq PE, Reding R, FK506 (Tacrolimus), A Novel Immunosuppressant in Organ Transplantation: Clinical, Biomedical, and Analytical Aspects. Clin Chem Vol.39: No 11: 1993.

10. Graham RM. Cyclosporine: Mechanisms of Action and Toxicity. Clev Clin J Med Vol. 61: No4: July-Aug, 1994. 
11. Johnson JP. Acquired Craniofacial Features Associated with Chronic Phenytoin Therapy. Clin Pediatr 1984; 23: 671-674.

12. Kennedy PA. Cephalometric Standards of Four, Five, Six, and Seven Year Old Latin American Children. Master's Thesis, University of Texas, 1969.

13. Reznik VM, Jones KL, Durham BL, Mendoza SA. Changes in Facial Appearance During Cyclosporin Treatment. Lancet II 1987; 1405-1407.

14. Reznik VM, Berger JS, Jones KL, Mendoza SA. Cyclosporin Induces Abnormal Facial Bone Growth in Children: A Preliminary Study. Ped Nephrology 1989; 3: 296-299.

15. Riolo ML et al: An atlas of craniofacial growth, monograph 2, craniofacial growth series, Ann Arbor, 1974, University of Michigan, Center for Human Growth and Development.

16. Broadbent $\mathrm{BH}, \mathrm{Sr}$, Broadbent $\mathrm{BH}, \mathrm{Jr}$, Golden $\mathrm{WH}$ : Bolten standards of dentofacial developmental growth, St Louis, 1975, Mosby-Year Book.

17. Steiner CC. Cephalometrics for you and me. AJO, 39: 729-755, 1953

18. Riedel RA. A cephalometric roentogenographic study of the relation of the maxilla and associated parts to the cranial base in normal and malocclusion of the teeth, Master's thesis, Northwestern University, 1948.

19. Downs WB. Variation in facial relasionships: Their significance in treatment and prognosis, AJO. 34: 812-840, 1948.

20. Krogman W, Sassouni V: A syllabus in roentogenographic cephalometry, Philadelphia, 1957, Philadelphia Center for Research in Child Growth.

21. Canavati PS. Cephalometric Standards for Four and Five Year Old Latin American Children. Master's Thesis, University of Texas, 1967. 
22. Greulich WW, Pyle SI. Radiographic Atlas of Skeletal Development of the Hand and Wrist. Stanford, CA, 1950, Stanford University Press.

23. Hamill PVV, Drizd TA, Johnson CL, Reed RB, Roche AF, Moore WM: Physical growth: National Center for Health Statistics percentiles. AM J CLIN NUTR 32:607-629, 1979.

24. Enlow DH: Handbook of facial growth, ed. 3, Philadelphia, 1990, WB Saunders.

25. Sarnat BG: Normal and abnormal craniofacial growth. Angle Orthod 53; 263-289, 1983.

26. Moyers RE: Handbook of Orthodontics, ed. 4, Chicago, 1988, Year Book Medical Publishers, Inc. 